\title{
Prevalence of dengue and chikungunya virus infections in north-eastern Tanzania: a cross sectional study among participants presenting with malaria-like symptoms
}

Debora C. Kajeguka ${ }^{1 *}$, Robert D. Kaaya ${ }^{1}$, Steven Mwakalinga ${ }^{1,3}$, Rogathe Ndossi', Arnold Ndaro³, Jaffu O. Chilongola ${ }^{1,3}$, Franklin W. Mosha', Karin L. Schiøler ${ }^{4}$, Reginald A. Kavishe ${ }^{1,3}$ and Michael Alifrangis ${ }^{2}$

\begin{abstract}
Background: In spite of increasing reports of dengue and chikungunya activity in Tanzania, limited research has been done to document the general epidemiology of dengue and chikungunya in the country. This study aimed at determining the sero-prevalence and prevalence of acute infections of dengue and chikungunya virus among participants presenting with malaria-like symptoms (fever, headache, rash, vomit, and joint pain) in three communities with distinct ecologies of north-eastern Tanzania.

Methods: Cross sectional studies were conducted among 1100 participants (aged 2-70 years) presenting with malaria-like symptoms at health facilities at Bondo dispensary (Bondo, Tanga), Hai hospital (Hai, Kilimanjaro) and TPC hospital (Lower Moshi). Participants who were malaria negative using rapid diagnostic tests (mRDT) were screened for sero-positivity towards dengue and chikungunya Immunoglobulin G and M (IgG and IgM) using ELISA-based kits. Participants with specific symptoms defined as probable dengue and/or chikungunya by WHO (fever and various combinations of symptoms such as headache, rash, nausea/vomit, and joint pain) were further screened for acute dengue and chikungunya infections by PCR.

Results: Out of a total of 1100 participants recruited, $91.2 \%(n=1003)$ were malaria negative by mRDT. Out of these, few of the participants $(<5 \%)$ were dengue lgM or lgG positive. A total of 381 participants had fever out of which $8.7 \%(33 / 381)$ met the defined criteria for probable dengue, though none $(0 \%)$ was confirmed to be acute cases. Chikungunya IgM positives among febrile participants were $12.9 \%$ (49/381) while IgG positives were at $3.7 \%(14 / 381)$. A total of $74.2 \%$ (283/381) participants met the defined criteria for probable chikungunya and $4.2 \%(11 / 263)$ were confirmed by PCR to be acute chikungunya cases. Further analyses revealed that headache and joint pain were significantly associated with chikungunya IgM seropositivity.

Conclusion: In north-eastern Tanzania, mainly chikungunya virus appears to be actively circulating in the population. Continuous surveillance is needed to determine the contribution of viral infections of fever cases. A possible establishment of arboviral vector preventive control measures and better diagnosis of pathogens to avoid over-treatment of other diseases should be considered.
\end{abstract}

Keywords: Dengue, Chikungunya, Arbovirus, Prevalence, Tanzania

\footnotetext{
* Correspondence: d7kajeguka@gmail.com

'Faculty of Medicine, Kilimanjaro Christian Medical University College, Moshi,

Kilimanjaro, Tanzania

Full list of author information is available at the end of the article
}

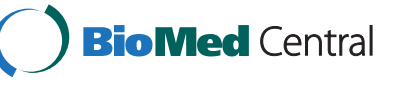

(c) 2016 Kajeguka et al. Open Access This article is distributed under the terms of the Creative Commons Attribution 4.0 International License (http://creativecommons.org/licenses/by/4.0/), which permits unrestricted use, distribution, and reproduction in any medium, provided you give appropriate credit to the original author(s) and the source, provide a link to the Creative Commons license, and indicate if changes were made. The Creative Commons Public Domain Dedication waiver (http://creativecommons.org/publicdomain/zero/1.0/) applies to the data made available in this article, unless otherwise stated. 


\section{Background}

Dengue and chikungunya are major global health concerns due to their continued spread and intensifying epidemic activities throughout most of the tropical and subtropical regions of the world. Regular outbreaks of dengue have been reported throughout most of the tropical and sub-tropical regions of the world for several decades [1-3] while chikungunya epidemics have attained global distribution within the past ten years; yet largescale epidemics of dengue fever and chikungunya fever has only recently presented as an emerging phenomenon in Africa [4].

These viruses are transmitted between humans by the bite of infected Aedes aegypti mosquitoes, furthermore chikungunya has increased its geographical range by its ability to infect Aedes albopictus [5, 6]. Most arbovirus infections are asymptomatic [7], but can as well cause a broad spectrum of manifestations, ranging from nonspecific flu-like syndrome to severe complications [8,9].

Tanzania, as many other African countries, is experiencing a shift in disease transmission patterns with regards to febrile infectious diseases. While the number of cases of malaria are decreasing in several countries of sub-Saharan Africa [10-13], the number of febrile cases due to other causes than malaria are still high [14]. Various arboviruses are most likely important and are gaining more prominence as observed through an increase in reported activity [15-18] and epidemic activity of diseases such as dengue and chikungunya [1, 19-21]. Moreover, malaria may as well have been over-diagnosed in different parts of Tanzania [22-24], mainly due to lack of differential pathogen diagnosis apart from malaria [25], including dengue and chikungunya. Recent studies in Tanzania have revealed that patients with acute dengue and chikungunya infection are often misdiagnosed and treated with anti-malarials or antibiotics [22, 26]. The consequences of misdiagnosis and underreporting of other diseases than malaria include economic loss [27], development of drug resistant malaria strains (due to over-prescribing of antimalarials) [28] and risks of increased morbidity and mortality [29].

Little is known about the general epidemiology of dengue and chikungunya in Africa and Tanzania in particular. Thus, the objective of this study was to determine the sero-prevalence and as well, prevalence of acute infections of dengue and chikungunya virus among participants presenting with malaria-like symptoms (fever, headache, rash, vomit, and joint pain) in three communities with distinct ecologies of North-eastern Tanzania.

\section{Methods}

\section{Study sites}

We conducted cross sectional studies at three sites in north-eastern Tanzania; Bondo dispensary (Bondo, Tanga),
Hai hospital (Hai, Kilimanjaro) and TPC hospital (Lower Moshi) in May 2013, November 2013 and May 2014, respectively. These sites were selected based on variation in precipitation pattern and varying altitude between the sites resulting in difference in malaria transmission, and as well, evidence of overdiagnosis of malaria [22]. Since most malaria and arbovirus transmission occur during the rainy seasons as a results of increased vector abundance, we chose to conduct the surveys during the rainy seasons that is in May and November. That is also the time when over diagnosis of malaria is most likely to occur. Bondo is a coastal lowland rural area in Handeni, Tanga region located $309 \mathrm{~m}$ above sea level. Bondo is endemic to malaria with a perennial transmission [30]. Hai is a sub-urban area situated on the South-western slope of Mount Kilimanjaro surrounded by three altitude zones ranging from highland (1,666-1,800 m), middle (900-1666 m) and lowland zone (900 m) above sea level. In Hai malaria transmission is classified as moderately high in lower altitude, moderate in mid-altitude and non-endemic in highland areas [31]. Lower Moshi is a lowland rural area located at the base of Mount Kilimanjaro at an altitude of $800 \mathrm{~m}$ above sea level. In Lower Moshi, malaria transmission occurs throughout the year [32, 33].

\section{Participant's recruitment and data collection}

Community sensitization to participate in the study was done through community leaders. Inhabitants aged 2 to 70 years with specific symptoms (fever, headache, rash, vomit, and joint pain) were encouraged to voluntarily go for testing at the health facilities at Bondo Dispensary Hai Hospital or TPC hospital. Individuals presenting at the health facilities were informed of the study and on voluntary participation. A written informed consent was obtained from all participants and from parents or guardians for children under 18 years of age who agreed to participate in the study. A questionnaire was used to collect demographic and clinical data such as age, gender and history of illness for each of the participants. All participants were screened for malaria by rapid diagnostic tests (SD BIOLINE Malaria Ag P.f/Pan) and malaria positive patients were treated with antimalarial according to national guidelines. In addition, auxiliary temperature measurement was done to detect febrile cases (>37.5 0C) and a blood sample of 0.5-1 mL was taken from all consenting participants. A subject number was assigned to each participant and used to label blood samples. All samples collected in this study were not linked to personal identifier.

\section{IgG and IgM ELISA for detection of anti-dengue and anti-chikungunya antibodies}

Serum was separated from whole blood by centrifugation and stored at $-20{ }^{\circ} \mathrm{C}$. Anti-dengue IgM and IgG 
were detected using a direct enzyme linked immunosorbent assay (ELISA) kit (SD Inc, Gyeonggi-do, Korea) while anti-chikungunya IgM and IgG were analysed using Indirect Elisa kits (SD, Gyeonggi-do, Korea and IBL international, Hamburg, Germany, respectively). All assays were performed according to the manufacturers' procedures and all serum samples were diluted 1 into 100 with sample diluent provided with the kits. The optical density (OD) was measured at $450 \mathrm{~nm}$ and the units of antibody concentration and cut-off values calculated as described by the manufacturers. Briefly, for the Anti-dengue IgM/IgG and IgM anti-chikungunya ELISAs the diagnostic cut-off value was calculated as the average OD of negative controls +0.300 . For the IgG chikungunya ELISA the threshold for positivity was based on the OD cut-off value of the cut-of control $+10 \%$.

\section{RNA extraction, CDNA synthesis and PCR}

Only serum samples from participants with specific symptoms (fever, headache, rash, nausea, and joint pain) who met World Health Organization (WHO) criteria [9, 34] for probable dengue and chikungunya definitions (see below) were further tested by polymerase chain reaction (PCR). Ribonucleic acid (RNA) was extracted from serum samples using the Boom method [35]. Briefly, $30 \mu \mathrm{l}$ of silica was added and immediately vortexed for $5 \mathrm{~s}$ followed by shaking for $10 \mathrm{~min}$ and centrifuged at 12,000 g for $15 \mathrm{~s}$. Supernatant was removed and silica pellets was washed twice with $1 \mathrm{ml}$ of L2 buffer (120 g of guanidine thiocyanate $\{\mathrm{GuSCN}\}$ in $100 \mathrm{ml}$ of $0.1 \mathrm{M}$ Tris- $\mathrm{HCl}, \mathrm{pH}$ 6.4), twice with $1 \mathrm{ml}$ of $70 \%$ ethanol and once with $1 \mathrm{ml}$ of acetone. Silica pellets was dried at $56{ }^{\circ} \mathrm{C}$ for $10 \mathrm{~min}$. RNA was eluted from the silica pellets in $50 \mu \mathrm{l}$ of diethyl pyrocarbonate (DEPEC) treated water and incubated for $10 \mathrm{~min}$ at $56{ }^{\circ} \mathrm{C}$. Sample was vortexed and centrifuged for $2 \mathrm{~min}$ at 12,000 g. $35 \mu \mathrm{l}$ containing purified RNA was transferred to an eppendorf tube and stored at $-20{ }^{\circ} \mathrm{C}$ prior to use. cDNA was synthesized using Superscript ${ }^{\circ}$ VILO $^{\text {tw }}$ cDNA synthesis kit (Invitrogen, life technologies, USA) according to manufacturer's instructions in a total volume of $20 \mu \mathrm{L}$ containing $2 \mu \mathrm{L}$ of 10X Superscript ${ }^{\circ}$ Enzyme Mix, $4 \mu \mathrm{L}$ of $5 \mathrm{X}$ VILO $^{\mathrm{mm}}$ reaction Mix, $11 \mu \mathrm{L}$ of DEPEC treated water (Ambion, USA) and $3 \mu \mathrm{L}$ of extracted RNA. The reverse transcription programme involved incubation at $25^{\circ} \mathrm{C}$ for $10 \mathrm{~min}$, extension at $42^{\circ} \mathrm{C}$ for $60 \mathrm{~min}$ and inactivation at $85^{\circ} \mathrm{C}$ for $5 \mathrm{~min}$. The resulting cDNA was stored in $-20{ }^{\circ} \mathrm{C}$ for further use for dengue and chikungunya PCR.

Dengue PCR was conducted as previously described [36] with respect to dengue only and with minor modifications using TaqMan Gene expression master mix kit (Applied Biosystens, USA). Briefly; the reaction mixture was composed of $5 \mu \mathrm{l}$ of TagMan Gene Expression master mix (Applied Biosystens, USA), $0.3 \mu \mathrm{l}$ of each
$0.25 \mu \mathrm{M}$ forward and reverse primer, $0.14 \mu \mathrm{L}$ of $0.125 \mu \mathrm{M}$ dengue probe, $3.37 \mu \mathrm{l}$ nuclease free water (NorgenBiotek, Canada), and $1 \mu \mathrm{l}$ of cDNA template in a final volume of $10 \mu \mathrm{l}$. The amplification reaction was performed in a Rotor-Gene Q PCR machine (Qiagen, Germany) with an initial denaturation at $95^{\circ} \mathrm{C}$ for 2 min followed by $45 \mathrm{cy}$ cles of denaturation at $95^{\circ} \mathrm{C}$ for $10 \mathrm{~s}$ and annealing and extension at $60{ }^{\circ} \mathrm{C}$ for minute. All primers and probes (Table 1) were purchased from BiolegioInc, Netherlands.

The primers (Table 1) used for conventional chikungunya PCR were adopted from Reddy et al., [37] to amplify a $646 \mathrm{bp}$ gene product in the chikungunya envelope region of E1 (genome position: 10524-11170). The reaction was carried out in a Bio-Rad tetrad 2, (Biorad, USA) in a $20 \mu \mathrm{l}$ volume containing $1 \mu \mathrm{L}$ of cDNA, $4 \mu \mathrm{L}$ of $5 \mathrm{X}$ reaction buffer, $1.8 \mu \mathrm{L}$ of $25 \mathrm{mM}$ $\mathrm{MgCl}_{2}, 1.8 \mu \mathrm{L}$ of $10 \mu \mathrm{M}$ dNTP, $0.5 \mu \mathrm{L}$ of $20 \mu \mathrm{M}$ of each primers, $0.3 \mu \mathrm{L}$ of Go-Tag Flex DNA polymerase, and $10.3 \mu \mathrm{L}$ of nuclease free water (NorgenBiotek, Canada). The PCR programme consisted of an initial denaturation at $95{ }^{\circ} \mathrm{C}$ for $2 \mathrm{~min}$ and 40 cycles of $30 \mathrm{~s}$ denaturation at $95{ }^{\circ} \mathrm{C}, 30 \mathrm{~s}$ annealing at $55{ }^{\circ} \mathrm{C}, 1 \mathrm{~min}$ elongation at $72{ }^{\circ} \mathrm{C}$ and final extension at $72{ }^{\circ} \mathrm{C}$ for $5 \mathrm{~min}$. The amplified gene products were identified by their molecular weights analyzed by electrophoresis on a $1.5 \%$ agarose gel stained with ethidium bromide and visualized under UV light.

Dengue primers and probeswereadopted from Pongsir et al., [36] for detection of dengue by real time PCR while for chikungunya the primers wereadopted from Reddy et al., [37] for chikungunya conventional PCR.

\section{Case definitions}

Dengue and chikungunya cases were classified according to WHO [9, 34]. In brief, probable dengue was defined as participants with fever and any two of the following criteria: nausea, vomiting, rash, pains, tourniquet test positive, leukopenia and/or a positive IgM ELISA test. Probable chikungunya: a patient meeting both the clinical (a characteristic triad of fever, rash and joint manifestations plus the following: nausea, vomiting, headache and/or an IgM positive test by ELISA) and epidemiological criteria (residing or having visited epidemic areas). Confirmed acute dengue or chikungunya was defined as a positive PCR result. Prior exposure was defined as presence of anti-dengue or anti-chikungunya IgG or IgM in serum.

\section{Statistical analyses}

Data were compiled and analyzed using SPSS 20.0 software (SPSS Inc., Chicago, IL, USA). Chi-square $(\chi 2)$ was used to compare categorical data while Fisher's exact test was used in cases when expected counts were less than 5. Association of chikungunya seropositivity and symptoms was analyses by logistic regression. A 
Table 1 Primers and Probe sequences used in detection of dengue and chikungunya

\begin{tabular}{llll}
\hline Sequence name & Primer sequence (5'-3') & Region, position & Digital object identifier (DOI) \\
\hline DENV-R & GHRGAGACAGCAGGATCTCTG & $3^{\prime}$ UTR, 10674-10694 & $10.1016 / 51995-7645(12) 60055-8$ \\
DENV-F & GACTAGYGGTTAGAGGAGACC & $3^{\prime}$ UTR, 10520-10541 & \\
DENV-P & Cy5-AAGGACTAGMGGTTAGWGGAGACCC-BHQ2 & $3^{\prime} U T R, 10610-10634$ & \\
CHIKV-F & CGTGGTGTACAAAGGTGACG & E1, 10524 & $10.1002 / j m v .23406$ \\
CHIKV-R & ACG CCG GGTAGTTGACTATG & E1, 11170 & \\
\hline
\end{tabular}

$P$-value $<0.05$ was considered statistically significant. Descriptive statistics are presented as medians and ranges for continuous variables after checking for normality and as proportions for categorical data.

\section{Results}

\section{Baseline characteristics}

Among patients presenting at Hai hospital (Hai district, Kilimanjaro), TPC hospital (Lower Moshi, Kilimanjaro) and Bondo Dispensary (Handeni, Tanga), 1100 participants were recruited $(n=240, n=549$ and $n=311$, respectively), of which $61.3 \%$ (674) were female and $61.6 \%$ (678) were adults ( $\geq 15$ years) (Table 2 ). The median age was 24 years (range; 2 to 70 years), with males having a

Table 2 Baseline characteristics of the studied population $(N=1100)$

\begin{tabular}{|c|c|c|c|c|c|}
\hline \multirow{2}{*}{\multicolumn{2}{|c|}{ Sites }} & \multicolumn{4}{|c|}{ Variable $\%(n)$} \\
\hline & & $\begin{array}{l}\text { Bondo } \\
n=549\end{array}$ & $\begin{array}{l}\text { Hai } \\
n=240\end{array}$ & $\begin{array}{l}\text { TPC } \\
n=311\end{array}$ & $\begin{array}{l}\text { Total } \\
N=1100\end{array}$ \\
\hline \multirow{3}{*}{ Sex } & & & & & \\
\hline & Male & $37.3(205)$ & $32.9(79)$ & $45.7(142)$ & $38.7(426)$ \\
\hline & Female & $62.7(344)$ & $67.1(161)$ & 54.3 (169) & $61.3(674)$ \\
\hline \multirow[t]{2}{*}{ Age } & Adults & $56.6(311)$ & $21.7(52)$ & $19.0(59)$ & $38.4(422)$ \\
\hline & Children & $43.4(238)$ & $78.3(188)$ & $81.0(252)$ & $61.6(678)$ \\
\hline \multicolumn{6}{|c|}{ Total Malaria (mRDT) } \\
\hline \multicolumn{2}{|c|}{ Positive } & $8.6(47)$ & $0(0)$ & $16.1(50)$ & $8.8(97)$ \\
\hline \multicolumn{2}{|c|}{ Negative } & $91.4(502)$ & $0(240)$ & $83.9(261)$ & 91.2 (1003) \\
\hline \multicolumn{2}{|c|}{ Malaria RDT } & $n=311$ & $n=52$ & $n=59$ & $n=422$ \\
\hline \multicolumn{2}{|c|}{ *In children - Positive } & $14.1(44)$ & $0(0)$ & $25.4(15)$ & $14.0(59)$ \\
\hline \multicolumn{2}{|c|}{ Negative } & $85.9(267)$ & $100(52)$ & $74.6(44)$ & $86.0(363)$ \\
\hline \multicolumn{2}{|c|}{ Malaria RDT } & $n=238$ & $n=188$ & $n=252$ & $n=678$ \\
\hline \multicolumn{2}{|c|}{${ }^{* *}$ In adults - Positive } & $1.3(3)$ & $0(0)$ & $13.9(35)$ & $5.6(38)$ \\
\hline \multicolumn{2}{|c|}{ Negative } & $98.7(235)$ & $100(188)$ & $86.1(217)$ & $94.4(640)$ \\
\hline \multicolumn{2}{|c|}{${ }^{\mathrm{a}}$ Fever in children } & $n=267$ & $n=52$ & $n=44$ & $n=363$ \\
\hline \multicolumn{2}{|c|}{ Positive } & $22.8(61)$ & $78.8(41)$ & $52.3(23)$ & $34.4(125)$ \\
\hline \multicolumn{2}{|c|}{ Negative } & $77.2(206)$ & $21.2(11)$ & $47.7(21)$ & $65.6(238)$ \\
\hline \multicolumn{2}{|c|}{${ }^{\mathrm{a}}$ Fever in adults } & $n=235$ & $n=188$ & $n=217$ & $n=640$ \\
\hline \multicolumn{2}{|c|}{ Positive } & $40.4(95)$ & $24.5(46)$ & $53.0(115)$ & $40.0(256)$ \\
\hline \multicolumn{2}{|c|}{ Negative } & $59.6(140)$ & 75.5 (142) & $47.0(102)$ & $60.0(384)$ \\
\hline
\end{tabular}

lower median age than females (median, 15.5 and 26 years, respectively). Generally, the malaria prevalence by $\mathrm{mRDT}$ was $8.8 \%$ (97/1100) while the remaining $91.2 \%$ (1003/ 1100) were malaria negative. The three sites varied significantly in malaria prevalence; among children (2 to 14 years), the malaria prevalence were highest in participating children attending TPC hospital with $25.4 \%$ $(15 / 59)$ followed by $14.1 \%(44 / 311)$ in Bondo dispensary and $0 \%$ in Hai hospital. Among adults ( $\geq 15$ years), the malaria prevalence were likewise highest in TPC hospital at $13.9 \%(35 / 252)$ followed by Bondo dispensary at $1.3 \%(3 / 238)$ and none in Hai hospital.

After excluding all malaria positive cases the prevalence of fever in children were highest in Hai hospital at $78.8 \%$ (41/52), followed by TPC hospital at $52.3 \%$ $(23 / 44)$ and Bondo dispensary at $22.8 \%(61 / 267)$. Among adults, the prevalence of fever were $53.0 \%(115 / 217)$ at TPC hospital, followed by Bondo dispensary at $40.4 \%$ (95/235) and lastly, in Hai hospital at $24.5 \%$ (46/188).

\section{Sero-prevalence of dengue and chikungunya among febrile and afebrile participants}

Among all febrile participants, the total prevalence of dengue IgM positives was $1.3 \%$ (5/381) all of which were from participants residing nearby TPC hospital (3.6 \% (5/138) (Table 3). The prevalence of Dengue IgG positives among febrile participants were as well low, only $1.3 \%(2 / 156)$ in Bondo dispensary, $1.1 \%(1 / 87)$ in Hai hospital and $1.4 \%(2 / 138)$ in TPC hospital. Among afebrile participants, the total prevalence of dengue IgM positives was only $0.8 \%(5 / 622)$ out of which $0.6 \%$ (2/346), $0.7 \%(1 / 153)$ and $1.6 \%(2 / 123)$ positives were observed in samples from Bondo dispensary, Hai hospital and TPC hospital, respectively. Conversely, dengue IgG positives were also low at the three sites.

Generally, we observed high IgM sero-prevalence among all participants while no difference between children $14.0 \%$ $(51 / 363)$ and adults $13.1 \%(84 / 640),\left(\chi^{2}=0.17 ; p=0.6\right)$ and IgG sero-prevalence was low with difference between children $3.0 \%(11 / 363)$ and adults $5.9(38 / 640)$, $\left(\chi^{2}=4.21 ; p=0.04\right)$. The total number of chikungunya IgM positives among febrile participants were $12.9 \%$ (49/381), and there were no difference observed between children $12.0 \%(14 / 49)$ and adults $13.3 \%(34 / 49)\left(\chi^{2}=\right.$ $0.12 ; p=0.7)$. No apparent differences between the sites 
Table 3 Seroprevalence of dengue and chikungunya among febrile and afebrile participants in north-eastern Tanzania ( $N=1003)$

\begin{tabular}{|c|c|c|c|c|c|c|c|c|}
\hline \multirow{3}{*}{ Sites } & \multicolumn{4}{|c|}{ Febrile $n(\%)$} & \multicolumn{4}{|c|}{ Afebrile $n(\%)$} \\
\hline & Bondo & Hai & TPC & Total & Bondo & Hai & TPC & Total \\
\hline & $n=156$ & $n=87$ & $n=138$ & $n=381$ & $n=346$ & $n=153$ & $n=123$ & $n=622$ \\
\hline Dengue IgM & ${ }^{\mathrm{a}} 0(0)$ & $0(0)$ & $3.6(5)$ & $1.3(5)$ & ${ }^{\mathrm{a}} 0.6(2)$ & $0.7(1)$ & $1.6(2)$ & $0.8(5)$ \\
\hline Dengue lgG & $\mathrm{a}_{1.3}(2)$ & $1.1(1)$ & $1.4(2)$ & $1.3(5)$ & $\mathrm{a} 1.2(4)$ & $0.7(1)$ & $0(0)$ & $0.8(5)$ \\
\hline Chikungunya IgM & $14.7(23)$ & $13.8(12)$ & $10.1(14)$ & $12.9(49)$ & $12.1(42)$ & $20.3(31)$ & $10.6(13)$ & $13.8(86$ \\
\hline Chikungunya IgG & ${ }^{a} 1.9(3)$ & $6.9(6)$ & $3.6(5)$ & $3.7(14)$ & $3.2(11)$ & $6.5(10)$ & $11.4(14)$ & $5.6(35)$ \\
\hline
\end{tabular}

IgM Immunoglobulin M, IgG Immunoglobulin G

${ }^{a}$ Difference was calculated by Fishers exact test

were observed; $14.7 \%(23 / 156)$ in Bondo dispensary, $13.8 \%(12 / 87)$ in Hai hospital and $10.1 \%(14 / 138)$ in TPC hospital $\left(\chi^{2}=1.46 ; p=0.4\right)$, (Table 3). The total number of IgG positives among febrile participants was lower; at $3.7 \%(14 / 381)$ divided into $1.9 \%(3 / 156)$ in Bondo dispensary, 6.9 \% (6/87) in Hai hospital and 3.6 \% (5/138) in TPC hospital (Table 3). Total number of IgG positives among febrile participants was not different between children $4.8 \%(6 / 14)$ and adults $3.1 \%(8 / 14)\left(\chi^{2}=0.66\right.$; $p=0.4$ ).

Among afebrile participants, the total number of chikungunya IgM positives was higher, as compared to the febrile participants, at $13.8 \%(86 / 622)$, though this was not significantly different $\left(\chi^{2}=0.189 ; p=0.6\right)$. Furthermore, the number of IgM positives was significantly different between the sites; $12.1 \%(42 / 346)$ in Bondo dispensary, $20.3 \%(31 / 153)$ in Hai hospital and $10.6 \%(13 / 123)$ in TPC hospital $\left(\chi^{2}=7.24 ; p=0.02\right)$. Likewise; the observed total chikungunya IgG positives was lower than the IgM positives, at $5.6 \%$ (35/622) though with a significant difference between the sites; $3.2 \%$ $(11 / 346)$ in Bondo dispensary, $6.5 \%(10 / 153)$ in Hai hospital and $11.4 \%(14 / 123)$ in TPC hospital $\left(\chi^{2}=11.81\right.$; $p=0.03$ ), (Table 3 ).

\section{Probable dengue and chikungunya}

Among all febrile participants, $8.7 \%$ (33/381) and $74.2 \%(283 / 381)$ cases met the WHO criteria for probable dengue and chikungunya respectively. None of the cases were positive for dengue while $4.2 \%(11 / 263)$ were confirmed acute chikungunya cases by PCR. Ten of the acute chikungunya cases were from Bondo and a single case came from Hai. Two of these cases were children (2 to 14 years).

\section{Association of chikungunya seropositivity and symptoms} In uni-variate analysis results, headache and joint pain were significant predictors of chikungunya IgM seropositivity with $\mathrm{OR}=3.03(2.06-4.4), p<0.01$ and $\mathrm{OR}=1.80$ (1.25-2.59), $p<0.01$ respectively. However when we combined headache and joint pain we did not observe any association, $\mathrm{OR}=0.84$ (0.55-1.26); $p=0.4$. Joint pain were marginally associated with chikungunya IgG seropositivity $\mathrm{OR}=0.51(0.26-0.9), p=0.05$, Tables 4 and 5 . Results of laboratory test among participants are presented in Additional file 1: Table 6.

\section{Discussion}

Diagnosis of infectious diseases in resource poor settings is a challenge. In malaria endemic areas most febrile illnesses have been and are treated as malaria cases due to lack of diagnostic capacity to properly rule-out malaria as a cause of fever and as well, identify alternative fever-causing pathogens [14]. As for malaria, diagnosis of dengue and chikungunya based on clinical presentation is difficult. Furthermore, similar presentations of signs and symptoms in the initial stage of illness of dengue and chikungunya have been a challenge to distinguish the two diseases clinically [38, 39]. Although, the vast majority of clinical dengue and chikungunya cases are self-limiting, however, in particularly diagnosis of patients with dengue is important for patient management in case of severe symptoms if done in a timely manner.

This study was conducted in three sites in northern Tanzania, each community have different characteristics in terms of varying altitude and thus, malaria transmission that may had identified acute cases of dengue and chikungunya infections and variations in prevalence of serological markers of dengue and chikungunya between the sites. Accordingly, the three sites differed in malaria prevalence with TPC hospital having higher malaria prevalence as compared to Bondo dispensary and Hai hospital as based on mRDT diagnosis.

We observed few dengue IgM positive cases among febrile participants in TPC hospital in Moshi (3.6 \%) and there were no confirmed acute dengue cases by PCR at any sites. Evidence shows that viral RNA can be detected in patients from 0-7 days following the onset of symptoms, which corresponds roughly to the duration of fever while IgM is detected in 3 to 5 or more days after the onset of illness/symptoms in the majority of infected individuals [40]. Therefore, there is a possibility that dengue IgM positive but PCR negative samples were 
Table 4 Association of symptoms and chikungunya IgM seropositivity

\begin{tabular}{|c|c|c|c|c|c|c|c|}
\hline \multirow[b]{2}{*}{ Symptoms } & \multirow[b]{2}{*}{$n$} & \multirow[b]{2}{*}{$\begin{array}{l}\text { Positive } \\
\%(n)\end{array}$} & \multirow[b]{2}{*}{$\begin{array}{l}\text { Negative } \\
\%(n)\end{array}$} & \multicolumn{2}{|c|}{ Univariate analysis } & \multicolumn{2}{|c|}{ Multivariate analysis } \\
\hline & & & & OR (95\% Cl) & $p$-value & OR (95\% Cl) & $p$-value \\
\hline \multicolumn{8}{|l|}{ Fever } \\
\hline Yes & 381 & $36.3(49)$ & $38.2(332)$ & $0.92(0.63-1.34)$ & 0.6 & - & - \\
\hline No & 622 & $63.7(86)$ & $61.8(536)$ & Reference & & & \\
\hline \multicolumn{8}{|l|}{ Rash } \\
\hline Yes & 9 & $0(0)$ & $1.0(9)$ & - & - & - & - \\
\hline No & 994 & $100(135)$ & $99.0(859)$ & Reference & & & \\
\hline \multicolumn{8}{|l|}{ Nausea } \\
\hline Yes & 83 & $7.4(10)$ & $8.4(73)$ & $0.87(0.43-1.73)$ & 0.6 & - & - \\
\hline No & 920 & $92.6(125)$ & $91.6(795)$ & Reference & & & \\
\hline \multicolumn{8}{|l|}{ Headache } \\
\hline Yes & 451 & $68.1(92)$ & $41.1(359)$ & $3.03(2.06-4.46)$ & $<0.001$ & $2.90(1.88-4.48)$ & $<0.001$ \\
\hline No & 522 & $31.9(43)$ & $58.6(509)$ & Reference & & Reference & \\
\hline \multicolumn{8}{|l|}{ Joint pain } \\
\hline Yes & 381 & $50.4(68)$ & $36.1(313)$ & $1.80(1.25-2.59)$ & 0.002 & $1.09(0.72-1.65)$ & 0.6 \\
\hline No & 622 & $49.6(67)$ & $63.9(555)$ & Reference & & Reference & \\
\hline
\end{tabular}

OR Odds ratio, $\mathrm{Cl}$ Confident interval

collected towards the end of the acute phase beyond the viral RNA detection phase. Furthermore, the lack of PCR confirmed cases in the study sites are suggestive of the IgM positive cases having been imported rather than locally transmitted. During the study, four cases who live in Moshi were reported from the KCMC hospital in
Moshi, a few kilometres from the TPC study site, after having visited Dar es Salaam during a large-scale dengue outbreak in April-May, 2014. These cases were PCRconfirmed by our study team (unpublished data). The sampling period for the TPC site coincides somewhat with the dengue outbreak in Dar es Salaam.

Table 5 Association of symptoms and chikungunyalg Gseropositivity

\begin{tabular}{|c|c|c|c|c|c|c|c|}
\hline \multirow[b]{2}{*}{ Symptoms } & \multirow[b]{2}{*}{$n$} & \multirow[b]{2}{*}{$\begin{array}{l}\text { Positive } \\
\%(n)\end{array}$} & \multirow[b]{2}{*}{$\begin{array}{l}\text { Negative } \\
\%(n)\end{array}$} & \multicolumn{2}{|c|}{ Univariate analysis } & \multicolumn{2}{|c|}{ Multivariate analysis } \\
\hline & & & & OR (95 \% Cl) & $p$-value & OR (95 \% Cl) & $p$-value \\
\hline \multicolumn{8}{|l|}{ Fever } \\
\hline Yes & 381 & $28.6(14)$ & $38.5(367)$ & $0.64(0.34-1.20)$ & 0.1 & $0.76(0.39-1.47)$ & 0.4 \\
\hline No & 622 & $71.4(35)$ & $61.5(587)$ & Reference & & Reference & \\
\hline \multicolumn{8}{|l|}{ Rash } \\
\hline Yes & 9 & $0(0)$ & $0.9(9)$ & - & - & - & - \\
\hline No & 994 & $100(49)$ & $99.1(945)$ & Reference & & & \\
\hline \multicolumn{8}{|l|}{ Nausea } \\
\hline Yes & 83 & $6.1(3)$ & $8.4(80)$ & $0.71(0.21-2.34)$ & 0.5 & - & - \\
\hline No & 920 & $93.9(46)$ & $91.6(874)$ & Reference & & & \\
\hline \multicolumn{8}{|l|}{ Headache } \\
\hline Yes & 451 & $40.8(20)$ & $45.2(431)$ & $0.83(0.46-1.50)$ & 0.5 & - & - \\
\hline No & 522 & $59.2(29)$ & $54.8(523)$ & Reference & & & \\
\hline \multicolumn{8}{|l|}{ Joint pain } \\
\hline Yes & 381 & $24.5(12)$ & 38.7 (369) & $0.51(0.26-0.9)$ & 0.05 & $0.56(0.28-1.11)$ & 0.1 \\
\hline No & 622 & $75.5(37)$ & $61.3(585)$ & Reference & & Reference & \\
\hline
\end{tabular}


Only $1.3 \%$ of the participants were IgG positive to dengue infection. This is lower than the previously reported (10.7 \%) in Moshi by Hertz et al. [26]. This can be explained by the fact that the study by Hertz et al. was based at a referral hospital receiving cases from the whole north-eastern Tanzania catchment area, while our study was conducted in health facilities serving local communities in each site. Although cross-reactivity with other flavivirus cannot be completely ruled-out, the sensitivity and specificity of the IgG ELISA kits used in this study are reported to be $99.2 \%$ and $96.2 \%$, respectively when compared to the hemagglutination-inhibition method and thus it is unlikely that the observed results are due to cross reactivity with other flavi-viruses.

Conversely, we identified a high sero-prevalence of chikungunya IgM (12.9\%) among febrile participants out of which $12.0 \%$ were among febrile children. This is the first report on chikungunya IgM positivity in the study sites. The proportion of chikungunya IgM seropositivity was comparable between children and adults thus indicating similar exposure among the two age groups. The $12 \%$ seropositivity observed in children ismore than twice as high as previously reported by Chipwaza et al. [41] in Kilosa, Morogoro (4.7 \%). This study found $5.6 \%$ of afebrile participants presenting with prior exposure to chikungunya infection as measured by IgG positivity. Since there is no routine diagnosis for this virus at the health facilities in the sites, it is likely that such infections go unnoticed or when causing fever end up being treated as other common infections such as malaria or bacterial infections. Unexpectedly, we observed that the number of chikungunya IgG positives were lower than the number of IgM positives. While the IgM positivity did not differ among children and adults, IgG positivity was significantly higher in adults (5.9\%) than in children $(3.0 \%)$. This is indicative of active circulation of chikungunya in the study sites as supported by PCR results, with adults having prior exposure which also points to a possible endemicity and cumulative increases in IgG seropositivity with age [42].

We identified an overall prevalence of $4.2 \%$ of acute chikungunya infections among study participants; with Bondo dispensary having the highest number of cases $(n=10,2.0 \%)$. This is somewhat lower than the previous reported in Kilimanjaro region of $7.9 \%$ [22, 26] however, taken together it seems that chikungunya, most likely as opposed to dengue, was endemic and actively circulating in North-eastern Tanzania at the time of the study.

However, it is not known whether the chikungunya virus was silent or been actively present in Tanzania because no research has been done for the past 60 years since its discovery [43] to document its distribution. Symptoms of chikungunya infection last for approximately 5 days, during which is the time the virus is present in the blood circulation and can be detected by PCR. After the viremic phase, sensitivity of diagnosis of acute infection is minimal [44] as the level of virus declines. We have observed few PCR positive in Hai and none in TPC (Lower Moshi) and this could be due to timing of blood sampling in acute infection.

The present study showed a significant association between clinical symptoms (joint pain and headache) and the probability of positive diagnosis of chikungunya IgM. These results are in line with other studies, that reported headache, nausea, vomiting, myalgia, and rash were associated with chikungunya infection $[45,46]$. We also observed association of chikungunya IgG seropositivity and joint pain. It is known that joint pain is one of the clinical features for chikungunya infection and its effect can persist for long [47-50]. However, these symptoms are common and non-specific, and thus could be mistakenly identified as caused by a variety of other febrile illnesses such as malaria, typhoid, dysentery, and bacterial meningitis $[51,52]$ and pose a challenge to differential diagnosis.

We did observe quite a low number of mRDT positives in the 3 sites; preliminary data suggest that, as expected, a fraction of the mRDT negatives are plasmodium positive when using a sensitive PCR method (data not shown), and therefore the low parasitaemi as are having no impact on fever/symptoms observed in participants, nevertheless after excluding all malaria positive, we found that $38.0 \%$ of the remaining participants reported fever. It is known that in many malaria endemic areas where clear diagnosis cannot be established, all fevers may still be treated as malaria [53]. Therefore, we recommend establishment of better diagnosis of fever to avoid over-treatment of other diseases.

\section{Conclusions}

This is the first seroprevalence report of dengue and chikungunya among participants presenting with malarialike symptoms in three communities with distinct ecologies of in north-eastern Tanzania. Chikungunya virus appears to be actively circulating in the population, while dengue circulates in low level. Among malarialike symptoms, headache was associated with chikungunya IgM seropositivity.

\section{Ethics approval and consent to participate}

Ethical approval for this study was obtained from the Kilimanjaro Christian Medical University College Research and Ethics Review Committee (CRERC) with a certificate number 658. A written informed consent was obtained from all participants and from parents or guardians for children under 18 years of age who agreed to participate in the study. 


\section{Additional file}

Additional file 1: Table S6. Labororatory results among probable and non-probable dengue and chikungunya. (XLSX $112 \mathrm{~kb}$ )

\section{Abbreviations}

BSU: building stronger university; CDC: centers for disease and control prevention; CDNA: complementary deoxyribo nucleic acid; CHIKV-F: chikungunya virus-forward; CHIKV-R: chikungunya virus-reverse; CRERC: College Research and Ethics Review Committee; DANIDA: Danish International Development Agency; DENV-F: dengue virus- forward; DENV-R: dengue virus- reverse; DEPEC: diethyl pyrocarbonate; DFC: Danida Fellowship Centre; ELISA: enzyme-linked immunosorbent assay; GuSCN: guanidine thiocyanate; lgG: immunoglobulin G; IgM: immunoglobulin M; MRDT: malaria rapid diagnostic test; OD: optical density; PCR: polymerase chain reaction; RNA: ribonucleic acid; SD: standard diagnostic; TPC: Tanzania plantations company; WHO: World Health Organization.

\section{Competing interests}

All authors declare that they have no competing interests.

\section{Authors' contributions}

DCK conceived the study, design and performed the study, analysed the data, and drafted the manuscript; RDK participated in field and lab work, and revised the manuscript; SM contributed to interpretation of data and critical review of the manuscript; RN participated in lab work and revised the manuscript. AN participated in field and lab work and revised the manuscript. JOC contributed to interpretation of data and critical review of the manuscript; FWM contributed to overall study design and critical review of the manuscript; KS contributed to overall study design, interpretation of data and critical review of the manuscript; RAK contributed to overall study design, analysis of data and critical review of the manuscript: MA contributed to overall study design, interpretation of data and critical review of the manuscript. All authors read and approved the final manuscript.

\section{Acknowledgements}

The authors would like to thank all volunteers who participated in the study in Bondo, Hai and TPC. The authors are in debt of gratitude to Ulla Abildtrup of Centre for Medical Parasitology, Denmark; Dr. Fausta Mosha of CDC Tanzania; Dr. Mike Drebot; Dr. Robbin Lindsay; Dr. Mahmood Iranpour and Kimberly Holloway of National Microbiology Laboratory, Winnipeg, Canada for providing controls and advice on chikungunya lab work.

\section{Funding}

Debora C. Kajeguka is supported by DANIDA through DFC in the Building strong Universities (BSU) project.

\section{Author details}

${ }^{1}$ Faculty of Medicine, Kilimanjaro Christian Medical University College, Moshi, Kilimanjaro, Tanzania. ${ }^{2}$ Centre for Medical Parasitology, Department Immunology and Microbiology, University of Copenhagen, Copenhagen, Denmark. ${ }^{3}$ Kilimanjaro Clinical research institute, Moshi, Kilimanjaro, Tanzania. ${ }^{4}$ Global Health Section, Department of Public Health, University of Copenhagen, Copenhagen, Denmark.

\section{Received: 15 December 2015 Accepted: 13 April 2016}

\section{Published online: 26 April 2016}

\section{References}

1. ProMed. Dengue/DHF Updates [Internet]. 2009 [Accessed date: 30 Aug 2015] Available from: http//www.promedmail.org/post/20091123.4016 Number: 20091123.4016.

2. HealthMap. Dengue Epidemic in Brazil. 2015 [Accessed date: 4 Nov 2015] Available from: http://www.healthmap.org/site/diseasedaily/article/dengueepidemic-brazil-51315.

3. Wang S, Chang K, Lu R, Wang W, Chen Y, Chen M, et al. Large Dengue virus type 1 outbreak in Taiwan. Emerg. Microbes Infect. [Internet]. 2015:4. Available from: http://www.nature.com/emi.

4. Schwarz NG, Girmann M, Randriamampionona N, Bialonski A, Maus D, Krefis AC, et al. Seroprevalence of antibodies against chikungunya, dengue, and Rift Valley fever viruses after febrile illness outbreak, Madagascar. Emerg Infect Dis. 2012;18:1780-6.

5. Reiter P, Fontenille D, Paupy C. Aedes albopictus as an epidemic vector of chikungunya virus: another emerging problem? Lancet Infect Dis. 2006;6:463-4

6. Tsetsarkin KA, Vanlandingham DL, McGee CE, Higgs S. A single mutation in Chikungunya virus affects vector specificity and epidemic potential. PLoS Pathog. 2007:3:1895-906.

7. Endy TP, Anderson KB, Nisalak A, Yoon IK, Green S, Rothman AL, et al. Determinants of inapparent and symptomatic dengue infection in a prospective study of primary school children in Kamphaeng Phet, Thailand. PLoS Negl. Trop. Dis. 2011;5(3).

8. Sam IC, Kamarulzaman A, Ong GSY, Veriah RS, Ponnampalavanar S, Chan YF, et al. Chikungunya virus-associated death in Malaysia. Trop Biomed. 2010;27:343-7.

9. WHO. Dengue guidelines for diagnosis, treatment, prevention and control [Internet]. WHO Libr. 2009 [Accessed date: 5 Apr 2014]. Available from: http://www.who.int/tdr/publications/documents/dengue-diagnosis.pdf.

10. Aregawi MW, Ali AS, Al-mafazy A, Molteni F, Katikiti S, Warsame M, et al. Reductions in malaria and anaemia case and death burden at hospitals following scale-up of malaria control in Zanzibar, 1999-2008. Malar J BioMed Central Ltd. 2011;10:46

11. O'Meara WP, Mangeni JN, Steketee R, Greenwood B. Changes in the burden of malaria in sub-Saharan Africa. Lancet Infect Dis Elsevier Ltd. 2010;10:545-55.

12. Ishengoma DS, Mmbando BP, Segeja MD, Alifrangis M, Lemnge MM, Bygbjerg IC. Declining burden of malaria over two decades in a rural community of Muheza district, north-eastern Tanzania. Malar J Malaria Journal. 2013;12:338

13. Karema C, Aregawi MW, Rukundo A, Kabayiza A, Mulindahabi M, Fall IS, et al. Trends in malaria cases, hospital admissions and deaths following scale-up of anti-malarial interventions, 2000-2010, Rwanda. Malar J. 2012;11:236.

14. D'Acremont V, Lengeler C, Genton B. Reduction in the proportion of fevers associated with Plasmodium falciparum parasitaemia in Africa: a systematic review. Malar J. 2010;9:240

15. Awando J, Ongus J, Ouma C, Mwau M. Seroprevalence of Anti-Dengue Virus 2 Serocomplex antibodies in out-patients with fever visiting selected hospitals in rural parts of western Kenya in 2010-2011: A cross sectional study. Pan Afr Med J. 2013;16:1-10.

16. Vairo F, Nicastri E, Meschi S, Schepisi MS, Paglia MG, Bevilacqua N, et al. Seroprevalence of dengue infection: a cross-sectional survey in mainland Tanzania and on Pemba Island, Zanzibar. Int J Infect Dis. 2012;16:e44-6.

17. Vairo F, Nicastri E, Yussuf SM, Cannas A, Meschi S, Mahmoud MAA, et al. IgG Against Dengue Virus in Healthy. Emerg Infect Dis. 2014;20:465-8.

18. Weller N, Clowes P, Dobler G, Saathoff E, Kroidl I, Ntinginya NE, et al. Seroprevalence of alphavirus antibodies in a cross-sectional study in southwestern Tanzania suggests endemic circulation of chikungunya. PLoS Negl Trop Dis. 2014;8:e2979.

19. Orengo P. State confirms outbreak of dengue fever in Mandera. Stand. Digit. News Pap. [Internet]. 2011; Available from: http://www.standardmedia. co.ke/?articlelD=2000043805\&story title=state?confirms-?outbreak?of?dengue??fever-?in?mandera\&pageNo=1. Accessed 15 October 2014.

20. Schwartz E, Meltzer E, Mendelson M, Tooke A, Steiner F, Gautret P. Detection on four continents of dengue fever cases related to an ongoing outbreak in Luanda, Angola, March to May 2013. Euro Surveill. [Internet]. 2013;18(21). Available from: www.eurosurveillance.org.

21. WHO. Dengue outbreak in the United Republic of Tanzania ( Situation as of 30 May 2014 ) [Internet]. 2014 [Accessed date: 30 Jul 2015]. Available from: http://www.afro.who.int/en/clusters-a-programmes/dpc/epidemic-a-pandemicalert-and-response/4155-dengue-outbreak-in-the-united-republic-of-tanzania30-may-2014.html.

22. Crump JA, Morrissey AB, Nicholson WL, Massung RF, Stoddard RA, Galloway RL, et al. Etiology of severe non-malaria febrile illness in Northern Tanzania: a prospective cohort study. PLoS Negl Trop Dis. 2013;7:e2324.

23. Harchut K, Standley C, Dobson A, Klaassen B, Rambaud-Althaus C, Althaus F, et al. Over-diagnosis of malaria by microscopy in the Kilombero Valley, Southern Tanzania: an evaluation of the utility and cost-effectiveness of rapid diagnostic tests. Malar J Malaria J. 2013;12:159.

24. Reyburn H, Mbatia R, Drakeley C, Carneiro I, Mwakasungula E, Mwerinde O, Saganda K, Shao J, Kitua A, Olomi R, Greenwood BM \& Whitty CJM. Overdiagnosis of malaria in patients with severe febrile illness in Tanzania: 
a prospective study. BMJ. [Online]. 2004; November: (329:1212). Available from: www.bmj.com.

25. Chandler CIR, Jones C, Boniface G, Juma K, Reyburn H, Whitty CJM. Guidelines and mindlines: why do clinical staff over-diagnose malaria in Tanzania? A qualitative study. Malar J. 2008;7:53.

26. Hertz JT, Munishi OM, Ooi EE, Howe S, Lim WY, Chow A, et al. Chikungunya and dengue fever among hospitalized febrile patients in northern Tanzania. Am J Trop Med Hyg. 2012;86:171-7.

27. Hume JCC, Barnish G, Mangal T, Armázio L, Streat E, Bates I. Household cost of malaria overdiagnosis in rural Mozambique. Malar J. 2008;7:33.

28. Wongsrichanalai C, Barcus MJ, Muth S, Sutamihardja A, Wernsdorfer WH. A review of malaria diagnostic tools: Microscopy and rapid diagnostic test (RDT). Am J Trop Med Hyg. 2007;77:119-27.

29. Oladosu OO, Oyibo WA. Overdiagnosis and Overtreatment of Malaria in Children That Presented with Fever in Lagos, Nigeria. ISRN Infect Dis. 2013;2013:1-6.

30. Chilongola J, Ndaro A, Tarimo H, Shedrack T, Barthazary S, Kaaya R, et al. Occurrence of pfatpase6 Single Nucleotide Polymorphisms Associated with Artemisinin Resistance among Field Isolates of Plasmodium falciparum in North-Eastern Tanzania. 2015. p. 2015.

31. Chandramohan D, Mswia R \& Setel P. Relationship between malaria endemicity and acute febrile illness mortality in children. Bulletin of the World Health Organization. [Online]. 2001;79(4):375-6. Available from: http://www.ncbi.nlm.nih.gov/pubmed/11357219.

32. Shekalaghe SA, Bousema JT, Kunei KK, Lushino P, Masokoto A, Wolters LR, et al. Submicroscopic Plasmodium falciparum gametocyte carriage is common in an area of low and seasonal transmission in Tanzania. Trop Med Int Health. 2007;12:547-53.

33. Shekalaghe S, Alifrangis M, Mwanziva C, Enevold A, Mwakalinga S, Mkali $H$, et al. Low density parasitaemia, red blood cell polymorphisms and Plasmodium falciparum specific immune responses in a low endemic area in northern Tanzania. BMC Infect Dis. 2009;9:69.

34. WHO. Guidelines for Prevention \& Control of Chikungunya Fever [Internet] World Heal. Organ. 2009 [Accessed date: 20 Jul 2014]. Available from: http://www.wpro.who.int/en/.

35. Boom R, Sol CJ, Salimans MM, Jansen CL, Wertheim-van Dillen PM, van der Noordaa J. Rapid and simple method for purification of nucleic acids. J Clin Microbiol. 1990;28:495-503.

36. Pongsiri P, Praianantathavorn K, Theamboonlers A, Payungporn S, Poovorawan Y. Multiplex real-time RT-PCR for detecting chikungunya virus and dengue virus. Asian Pac J Trop Med Hainan Medical College. 2012;5:342-6.

37. Reddy V, Ravi V, Desai A, Parida M, Powers AM, Johnson BW. Utility of IgM ELISA, TaqMan real-time PCR, reverse transcription PCR, and RT-LAMP assay for the diagnosis of Chikungunya fever. J Med Virol. 2012;84:1771-8.

38. Mardekian SK, Roberts AL. Diagnostic Options and Challenges for Dengue and Chikungunya Viruses. Biomed Res. Int. [Internet]. 2015; Available from: http://dx.doi.org/10.1155/2015/834371.

39. Satheesh G, Prabhu NP, Venkataramana M. 3D Modeling of dengue virus NS4B and Chikungunya virus nsP4: identification of a common drug target and designing a single antiviral inhibitor. Curr Comput Aided Drug Des. 2014;10(13):361-73.

40. Peeling RW, Artsob H, Pelegrino JL, Buchy P, Cardosa MJ, Devi S, Enria DA Farrar J, Gubler DJ, Guzman MG, Halstead SB, Hunsperger E, Kliks S, Margolis HS, Nathanson CM, Nguyen VC, Rizzo N, Vazquez S \& Yoksan S. Evaluation of diagnostic tests: dengue. Nat Rev Microbiol. 2010;8(12):530-538. [Online] Available from: http://nature.com/reviews/micro.

41. Chipwaza B, Mugasa JP, Selemani M, Amuri M, Mosha F, Ngatunga SD Gwakisa PS. Dengue and Chikungunya Fever among Viral Diseases in Outpatient Febrile Children in Kilosa District Hospital , Tanzania. PLoS Negl Trop Dis. 2014;8(11). doi:10.1371/journal.pntd.0003335

42. Sutherland LJ, Cash AA, Huang YS, Sang RC, Malhotra I, Moormann AM, et al. Short Report: Serologic Evidence of Arboviral Infections among Humans in Kenya. Am J Trop Med Hyg. 2011;85:158-61.

43. Lumsden WH. An epidemic of virus disease in Southern Province, Tanganyika Territory, in 1952-53. II. General description and epidemiology. Trans R Soc Trop Med Hyg. 1955;49:33-57.

44. Dash M, Mohanty I, Padhi S. Laboratory diagnosis of chikungunya virus: do we really need it? Indian J Med Sci. 2011;65(3):83-91.

45. Mwongula AW, Mwamburi LA, Matilu M, Siamba DN, Wanyama FW. Seroprevalence of Chikungunya Infection in Pyretic Children Seeking
Treatment in Alupe District Hospital, Busia County Kenya. Int J Curr Microbiol App Sci. 2013;2:130-9.

46. Sissoko D, Ezzedine K, Moendandzé A, Giry C, Renault P, Malvy D. Field evaluation of clinical features during chikungunya outbreak in Mayotte, 2005-2006. Trop Med Int Health. 2010;15:600-7.

47. Borgherini G, Poubeau P, Jossaume A, Gouix A, Cotte L, Michault A, et al. Persistent Arthralgia Associated with Chikungunya Virus: A Study of 88 Adult Patients on Reunion Island. Clin Infect Dis. 2008:47:469-75.

48. Borgherini G, Poubeau P, Staikowsky F, Lory M, Le Moullec N, Becquart JP, et al. Outbreak of chikungunya on Reunion Island: early clinical and laboratory features in 157 adult patients. Clin Infect Dis. 2007:44:1401-7.

49. CDC. Chikungunya symptoms, Diagnosis and Treatment. 2015 [Accessed date: 25 Nov 2015]; Available from: http://www.cdc.gov/chikungunya/ symptoms/.

50. Schilte C, Staikovsky F, Couderc T, Madec Y \& Carpentier F. Chikungunya Virus-associated Long-term Arthralgia : A 36-month Prospective Longitudinal Study. PLoS neglected tropical diseases. 2013;7(3).

51. Dash AP, Rajesh B, Sunyoto T, Mourya D. Emerging and re-emerging arboviral diseases in Southeast Asia. J Vector Borne Dis. 2013:50:77-84

52. Sang $C$. The growing threat of arbovirus transmission and outbreaks in Kenya. East Africa Med J. 2001;78(12):655-61.

53. Mwanziva C, Manjurano A, Mbugi E, Mweya C, Mkali H, Kivuyo MP, et al. Defining malaria burden from morbidity and mortality records, self treatment practices and serological data in Magugu, Babati district, northern Tanzania. Tanzan J Health Res. 2011;13:1-12.

\section{Submit your next manuscript to BioMed Central and we will help you at every step:}

- We accept pre-submission inquiries

- Our selector tool helps you to find the most relevant journal

- We provide round the clock customer support

- Convenient online submission

- Thorough peer review

- Inclusion in PubMed and all major indexing services

- Maximum visibility for your research

Submit your manuscript at www.biomedcentral.com/submit
C Biomed Central 